\title{
The first year students' adaptation to the study of linguistic disciplines in the Framework of federal state educational standards of higher education (FSES of HE) realization of a new generation
}

\author{
Marina V. Sturikova - Irina M. Kondyurina - Nina V. Albrecht - Alena A. \\ Evtugina - Svetlana V. Smirnova
}

DOI: 10.18355/XL.2017.10.04.13

\begin{abstract}
The relevance of the research problem due to the need for effective adaptation of the first year students to the study of linguistic disciplines in the framework of Federal state educational standards of higher education realization of a new-generation, for getting information on the difficulties faced by the first-year students due to the appearance of new disciplines, innovative curricula, forms and methods of training, as well as the interest of organizers of educational process in high school in the high results of development of educational, personal and professional competences. The goal of the article lies in justification of the possibility and necessity of conducting various activities, which aimed at the successful adaptation of the students. The leading method to the study of this problem is empirical, which allows to monitor the process of adaptation of the first-year students, to carry out the measurement using a specially developed assignments, tests, etc., and comparison of the indicators; as well as the methods of mathematical statistics and graphical display of results. The set of activities are developed and tested which is necessary and sufficient for the efficient adaptation of the first-year students: organization of the tutors' work, the use of game situations on a professional theme, various activities outside the classroom, etc. The article can be useful in practical work of linguistic disciplines teachers not only in universities, but also at schools, colleges, as well as interesting to all who are connected with the professional pedagogical activity.
\end{abstract}

Key words: adaptation, student, linguistic disciplines, Federal state educational standards of higher education (FSES of HE) of a new generation

\section{Introduction}

Nowadays, the high school faces many problems, one of which is a problem, which associated with difficulties of the first year of study at the University, in particular with the adaptation of the students. Adaptation of the first year students to the study of linguistic disciplines in the framework of Federal state educational standards of higher education realization (FSES of HE) of a new generation, indeed, constitutes one of the important theoretical problems due to the fact that the adaptation of school graduates to the study at the University is a complex and multifarious process requiring the involvement of social and biological reserves of the body. The search problem is primarily related to the need of obtain information about the difficulties that are present in the educational process in the conditions of higher education reform, introduction of the new educational standards, disciplines and innovative educational programs, forms and methods of training. The relevance of our research due to the interest of organizers of educational process in high school in the high results of formation of students' educational, personal and professional competencies.

The main subject of our research is to study the problems of adaptation of students to the perception of linguistic disciplines with the aim of preparing the graduate for the future work as a highly qualified professional specialist who "knows how to adapt to different conditions and must possess high professional qualities, in whom there is a real need in the public and private enterprises" (Kondyurina, 2012). 
The adaptation stage at the University cannot be considered as spontaneously formed from the interaction of student with classmates, tutors, teachers, employees of the dean's office and other services, it is a controlled process based on the relevant performance indicators.

A recent graduate of the school, who comes into the high school, experiences some difficulties, which are usually called as a process of adaptation. "Adaptation is a complex and multilevel process that involves both psychological and social, and pedagogical components. The process of adaptation becomes vital when a person begins to interact with the environment, which has misalignment and the need for change and dictates all actions to individual" (Novikova, 2016).

The first time of University studies is often associated for students with stressful situations, therefore, the more successful and active will be a period of adaptation, the higher will be the level of professional training of students and assimilation of knowledge. The first year student adapts to the new conditions of training, life; changing its interaction with the education system due to the fact that there are some conditions in which old forms of behavior are ineffective. The student is forced to look for the new forms of behavior to overcome the current difficulties. Thus, the problem of student adaptation to the conditions of modern education is one of the key problems of education.

A careful study of the research on this issue leads to the conclusion that "some aspects of the adaptation process of students are still insufficiently studied and require more detailed consideration" (Astrakhanzeva \& Shinkoruk, 2015).

The initial stage of training in higher education is associated with a change of old stereotypes, social change, stressful situations, etc. It can lead many students to pseudo-sense of adulthood in such actions as leisure visits to the classroom, external forms of realization of his "I". All of this can go into a lack of desire to learn, to attend college, to participate in public and cultural life, so it should be paid a great attention to the organizational and educational work in junior courses (Lavrinenko, 2014).Let's select four stages of the first-year students' adaptation at the University to a new sociocultural environment:

1. The initial stage: the student understands how to behave in the new social environment, but he is not ready to accept and recognize the new value system of the University, therefore, he tends to seek usual system of values.

2. The tolerance stage: there is a mutual tolerance for patterns of behavior and system of values between the student group and the new environment.

3. Accommodation: the student accepts and acknowledges the system of values in the new environment and at the same time, a group (a new socio-cultural environment) recognizes the value of the student.

4. Assimilation: the system of the student's value and the group (a new socio-cultural environment) coincide.

Among the factors affecting the adaptation of freshmen to the University, we distinguish three components: sociological, psychological and pedagogical.

Sociological component includes the place of residence and social background of the student, his age, education and etc. The psychological component includes the intelligence of the student, his position in the group, personal potential, etc. Pedagogical component includes the organization of the educational environment, the level of pedagogical skills, material and technical base of the University.

The strategies of the first year students' adaptation of the higher school can be divided into active and passive, the active is the student's ability to change himself, to adapt to a new sociocultural environment; the passive is passively waiting for the changes within himself, the inability to adapt to a new sociocultural environment, the expectation of external changes. The student's inability to fit into the new social relations could entail his loss of interest in learning, even in the presence of previously

XLinguae, Volume 10, Issue 4, October 2017, ISSN 1337-8384, eISSN 2453-711X 
unmotivated high sense of maturity, which can manifest in the freedom of attendance, lack of desire to participate in public life, the strict control of the teachers etc. It is very important to educate the first year student's sense of autonomy, i.e. the capacity to control his behavior. The component of independence is a specially organized independent work of students in classroom and extracurricular activities, which is a way of active, deliberate acquisition of a student new knowledge and skills without the direct participation of teachers.

In the process of preparation of future specialists, we pay great attention to the cooperation between the student and the teacher, the result of which is a creative thinking personality, the key features are competitiveness, competence and autonomy. "It is important to bring to the learning process subject-subject relationship between the student and the teacher. That is, the teacher should not devote the bulk of training time to lecture and to be the translator of the main provisions and objectives of studying science. The main task of the teacher is to teach students how to learn, and the ability to produce knowledge and to match them, to draw conclusions and to rethink existing data in a new way. And the task of the learner is not passively accept the information given by the teacher in the classroom, but to be a partner of the educational process, actively work on its formation, to be the object of education rather than a subject" (Novikova, 2016; Cao, Kirilova, Grunis, 2017; Cai et al., 2017; Shen et al., 2017).

The first year students' adaptation to the study of linguistic disciplines in the framework of FSES of HE of a new generation assumes that "exit" "from one educational program should naturally "dock" with the "entrance" to the next, i.e. the required end-to-end standardization of all programs on the basis of common objectives of the whole system of studying linguistic disciplines is necessary. "Such natural combination of the output from one educational program with the input subsequently provides the student or specialist the ability to move freely in the educational space. The implementation of this principle is accompanied by many difficulties. This is due to the fact that this realization applies not only to the succession of the state standards, but also educational programs" (Fedorov, 2000).

The conditions for the effectiveness of the first year students' adaptation to the study of linguistic disciplines in the framework of FSES of HE of a new generation are the inclusion of students and co-teacher organization, control and selfcontrol of their professionally important academic work; integrated application of active forms, methods of training and specially designed tasks aimed at formation of self-organization competences of students' educational-professional activity. Due to the fact that the students ' adaptation to the new environment of the University is multifactorial, the role of pedagogical process management is big. To ensure effective adaptation of students to the new educational environment, you must perform such conditions: to study the personality characteristics of the first-year students; to identify the difficulties of the adaptation period and especially in the study of linguistic disciplines; to organize practical training in such a way that they enhanced the skills of constructive communication; to organize individual and students' group counseling.

That the adaptation of the first year students to the study of linguistic disciplines was effective, not only freshmen, but also teachers of these disciplines are interested.

The successful beginning of learning helps the student in his further study, gives positive effect on building relationships within the team and with the teachers. The student's personal development and further professional career depends from that how successful will be his adaptation

Nowadays, the high school faces many problems, one of which is a problem, which associated with difficulties of the first year of study at the University, in particular with the adaptation of the students. Adaptation of the first year students 
to the study of linguistic disciplines in the framework of Federal state educational standards of higher education realization (FSES of HE) of a new generation, indeed, constitutes one of the important theoretical problems due to the fact that the adaptation of school graduates to the study at the University is a complex and multifarious process requiring the involvement of social and biological reserves of the body. The search problem is primarily related to the need of obtain information about the difficulties that are present in the educational process in the conditions of higher education reform, introduction of the new educational standards, disciplines and innovative educational programs, forms and methods of training. The relevance of our research due to the interest of organizers of educational process in high school in the high results of formation of students' educational, personal and professional competencies.

The main subject of our research is to study the problems of adaptation of students to the perception of linguistic disciplines with the aim of preparing the graduate for the future work as a highly qualified professional specialist who "knows how to adapt to different conditions and must possess high professional qualities, in whom there is a real need in the public and private enterprises" (Kondyurina, 2012).

The adaptation stage at the University cannot be considered as spontaneously formed from the interaction of student with classmates, tutors, teachers, employees of the dean's office and other services, it is a controlled process based on the relevant performance indicators.

A recent graduate of the school, who comes into the high school, experiences some difficulties, which are usually called as a process of adaptation. "Adaptation is a complex and multilevel process that involves both psychological and social, and pedagogical components. The process of adaptation becomes vital when a person begins to interact with the environment, which has misalignment and the need for change and dictates all actions to individual" (Novikova, 2016).

The first time of University studies is often associated for students with stressful situations, therefore, the more successful and active will be a period of adaptation, the higher will be the level of professional training of students and assimilation of knowledge. The first year student adapts to the new conditions of training, life; changing its interaction with the education system due to the fact that there are some conditions in which old forms of behavior are ineffective. The student is forced to look for the new forms of behavior to overcome the current difficulties. Thus, the problem of student adaptation to the conditions of modern education is one of the key problems of education.

A careful study of the research on this issue leads to the conclusion that "some aspects of the adaptation process of students are still insufficiently studied and require more detailed consideration" (Astrakhanzeva, Shinkoruk, 2015).

The initial stage of training in higher education is associated with a change of old stereotypes, social change, stressful situations, etc. It can lead many students to pseudo-sense of adulthood in such actions as leisure visits to the classroom, external forms of realization of his "I". All of this can go into a lack of desire to learn, to attend college, to participate in public and cultural life, so it should be paid a great attention to the organizational and educational work in junior courses (Lavrinenko, 2014). Let's select four stages of the first-year students' adaptation at the University to a new sociocultural environment:

1. The initial stage: the student understands how to behave in the new social environment, but he is not ready to accept and recognize the new value system of the University, therefore, he tends to seek usual system of values.

2. The tolerance stage: there is a mutual tolerance for patterns of behavior and system of values between the student group and the new environment. 
3. Accommodation: the student accepts and acknowledges the system of values in the new environment and at the same time, a group (a new socio-cultural environment) recognizes the value of the student.

4. Assimilation: the system of the student's value and the group (a new socio-cultural environment) coincide.

Among the factors affecting the adaptation of freshmen to the University, we distinguish three components: sociological, psychological and pedagogical.

Sociological component includes the place of residence and social background of the student, his age, education and etc. The psychological component includes the intelligence of the student, his position in the group, personal potential, etc. Pedagogical component includes the organization of the educational environment, the level of pedagogical skills, material and technical base of the University.

The strategies of the first year students' adaptation of the higher school can be divided into active and passive, the active is the student's ability to change himself, to adapt to a new sociocultural environment; the passive is passively waiting for the changes within himself, the inability to adapt to a new sociocultural environment, the expectation of external changes. The student's inability to fit into the new social relations could entail his loss of interest in learning, even in the presence of previously unmotivated high sense of maturity, which can manifest in the freedom of attendance, lack of desire to participate in public life, the strict control of the teachers etc. It is very important to educate the first year student's sense of autonomy, i.e. the capacity to control his behavior. The component of independence is a specially organized independent work of students in classroom and extracurricular activities, which is a way of active, deliberate acquisition of a student new knowledge and skills without the direct participation of teachers.

In the process of preparation of future specialists, we pay great attention to the cooperation between the student and the teacher, the result of which is a creative thinking personality, the key features are competitiveness, competence and autonomy. "It is important to bring to the learning process subject-subject relationship between the student and the teacher. That is, the teacher should not devote the bulk of training time to lecture and to be the translator of the main provisions and objectives of studying science. The main task of the teacher is to teach students how to learn, and the ability to produce knowledge and to match them, to draw conclusions and to rethink existing data in a new way. And the task of the learner is not passively accept the information given by the teacher in the classroom, but to be a partner of the educational process, actively work on its formation, to be the object of education rather than a subject" (Novikova, 2016).

The first year students' adaptation to the study of linguistic disciplines in the framework of FSES of HE of a new generation assumes that "exit" "from one educational program should naturally "dock" with the "entrance" to the next, i.e. the required end-to-end standardization of all programs on the basis of common objectives of the whole system of studying linguistic disciplines is necessary. "Such natural combination of the output from one educational program with the input subsequently provides the student or specialist the ability to move freely in the educational space. The implementation of this principle is accompanied by many difficulties. This is due to the fact that this realization applies not only to the succession of the state standards, but also educational programs" (Fedorov, 2000).

The conditions for the effectiveness of the first year students' adaptation to the study of linguistic disciplines in the framework of FSES of HE of a new generation are the inclusion of students and co-teacher organization, control and selfcontrol of their professionally important academic work; integrated application of active forms, methods of training and specially designed tasks aimed at formation of self-organization competences of students' educational-professional activity. Due to the fact that the students ' adaptation to the new environment of the University is 
multifactorial, the role of pedagogical process management is big. To ensure effective adaptation of students to the new educational environment, you must perform such conditions: to study the personality characteristics of the first-year students; to identify the difficulties of the adaptation period and especially in the study of linguistic disciplines; to organize practical training in such a way that they enhanced the skills of constructive communication; to organize individual and students' group counseling.

That the adaptation of the first year students to the study of linguistic disciplines was effective, not only freshmen, but also teachers of these disciplines are interested.

The successful beginning of learning helps the student in his further study, gives positive effect on building relationships within the team and with the teachers. The student's personal development and further professional career depends from that how successful will be his adaptation

\section{Literature review}

Teaching in higher education is a new stage in the professional development of a young person and entails significant changes in his lifestyle, organization of educational and extracurricular activities, specialization of educational material, monitoring and self-learning activities and etc. A student tries his strength as a future specialist, professional in this period of formation and for us, this period is the subject of the study.

The problem of the first-year students' adaptation to educational process at the University is not new and draws attention of many scientists and teachers. The general problems of the first-year students' adaptation are considered in works of such scientists, as Kuzmishkin (2014), Kusakina (2011), Nalivaiko, Shinkaruk (2014), Smirnov (1998), Afonina, Uvarova (2001). Abroad this issue was paid attention such scientists, as Hoare (2006), Lopez-Fernandez, Rodrigues-Illera (2009), Morales (2009), Sippel (2007), Li, Pyrkova, Ryabova (2017), Cao, Kirilova, Grunis (2017), Li, Pyrkova, Ryabova (2017) and others.

Didactic, organizational and pedagogical conditions of the first-year students' adaptation to training in higher education institution are considered in the scientific works of modern Russian researchers, such as Sedin, Leonova (2009), Alyokhin, Andrushevich (2009), Lesnikova, Belyanina (2011), Gaponova (1994), Molokova (2015), Radnaeva, Shibanova (2016), Kazakov, Zakirova, Bírová (2017), Gorbunova, Mokeyeva (2017), Golubkova, Masalimova, Bírová (2017), Cai et al. (2017), Shen et al. (2017) and others.

The definition of the term "adaptation" in modern research is formulated as an adaptation to something, such explanation is confirmed by the etymology of the word: "adaptation" (from latin Adapto means fixture, fitting) (Zinchenko, 2007). According to Dermanova, Sidorenko (2003) "a person adapts growing in the environment. The effect of growing is provided through activity of the individual own resources, which directed at self-transformation. A person maximum focused on the change within themselves to achieve compliance with the new conditions" (Dermanova, Sidorenko, 2003). A student reveals his individuality, his personal potential, his spiritual and physical capabilities by adapting. "Effective adaptation ... is one of the prerequisites for successful professional or educational and professional activities" (Sheveleva, 2014).

Adaptation of the student in our understanding is a process of active adaptation of the individual to the new conditions, norms and values of the social environment. In sociology the concept of "adaptation" is a form of human behavior, appropriate personal qualities. In "the Pedagogical dictionary" Kodzhaspirova, Kodzhaspirov (2001) divorce the concepts of social and psychological adaptation:

XLinguae, Volume 10, Issue 4, October 2017, ISSN 1337-8384, eISSN 2453-711X 
social adaptation is 1) active adaptation of a person to the changed environment by forming himself the new ways of behavior, which aims to harmonize relationships with others; 2) optimization of the relationship of the individual and his group; 3) the process and the result of mastering by the student the new social roles and positions, significant for the student and his social environment. Mental adaptation is: a mental phenomenon, which is expressed in the restructuring of the stereotype of the individual in accordance with the new requirements of the environment (Kodzhaspirova, Kodzhaspirov, 2001).

We identify three forms of adaptation: physiological (a student adapts to the changing conditions of life); social-psychological (a student adapts to the new conditions of life) and academic (a student tries to adapt to the new pedagogical system).

On efficiency of students' adaptation to the new conditions of education influence psychological and pedagogical conditions. The most important of such conditions are "psycho-pedagogical diagnosis with the purpose of identifying individual personality characteristics of students and development of practical recommendations to the organization of work on adaptation of students for tutors and deans' offices, the establishment of the relationship between participants of educational process, improvement of the educational environment and the quality of training of students; the development of a number of disciplines aimed at formation of constructive interaction's skills, development of independence, reflection; adjustment of working programs, the content of which can include information about the organization of educational process in high school, the forms of current, intermediate and final control, organization of independent work of students, etc., integration of efforts of the Institute of curators, deans, student government, inclusion in the program of educational work activities aimed at the development of youth initiatives (volunteer movement, charity events, labor camps, etc.) (Radnaeva, Shibanova, 2016).

The students' adaptation has a great influence of subjective factors, among them are the level of readiness of students, skills of educational activities, the level of activity in the solution of educational tasks, etc.; and objective factors, which include the content and organization of educational activities in higher education; forms of control and evaluation of learning activities, the nature of educational interaction, living conditions etc.

"The success of the student in the learning process, and later as a young specialist depends on its successful adaptation in higher education institution" (Kruchinina, Daryenkov, 2016).The students' adaptation to training in higher educational institution is the criterion, and at the same time a condition of effectiveness of the educational process in general. There are four main factors that determine the success of the formation of students 'adaptation to learning in higher educational institution: students' attitude to the chosen profession, the initial condition of student's health, the structure of the educational process, organization of student life. The result of the process of students ' adaptation to learning in higher educational institution is their adaptability. It is achieved primarily through personal adaptation of the student's potential.

\section{Materials and Methods}

\subsection{Research methods}

The following methods were used during research: theoretical (study and analysis of philosophical, psycho-pedagogical, scientific-methodical literature, materials of international scientific-practical conferences, dissertations on the research topic, innovative educational technologies analysis of the concept of "adaptation", highlighting the stages of adaptation of students under the new educational standards; synthesis of theoretical scientific approach to the adaptation of first-year students and practical experience; a synthesis of the main results of the study); empirical 
(observation of the process of the first-year students' adaptation, measuring performance through specially developed assignments, tests, etc., comparison of indicators); experimental (formative experiment); methods of mathematical statistics and graphical display of results.

\subsection{Research Stages}

Skilled experimental base of the research was conducted at the Russian state vocational-pedagogical University, the Urals Institute of State fire service of EMERCOM of Russia.

Experimental work was carried out in three stages:

In the first stage, the design was defined by subjects, the materials of which was assumed the experimental work: "The Russian language and the culture of speech", "Stylistics of the scientific text", "Rhetoric", "Foreign language". At this stage, the methods of pedagogical projecting in the natural conditions of professional pedagogical University, analysis of terms and concepts, participant observation, questionnaires, etc. were used.

In the second stage, forming, different variants of the experimental materials: game situation on a professional theme, tests, assignments, exercises, questions, tests, texts on pedagogy and education, as well as texts on specialty were developed and tested. The main research methods were the methods of study and generalisation of pedagogical experience, the survey, monitoring, measurement and control, expert evaluations, the experimental research work, introduction of innovations in educational organizations.

In the third stage, correction, additions were made to the content of the study, the treated, clarified and summarized the results, conclusions. The methods of the results' interpretation, questionnaires and etc. were also used.

\section{Results and discussion}

To achieve more effective results of the first year students' adaptation to the study of linguistic disciplines in the framework of FSES of HE of a new generation, in the course of experimental work we use various methods, including the method of observation and recording of the results; interviews with students, participating in the experiment; testing of students; performing specially designed tasks, the learning performance of students, as well as interactive teaching methods due to the fact that the required methods are focused on active joint educational activity of the teacher and the students, their interaction and communication; they allow you to create such educational environment where the student "finds ways for maximum self-realization" (Sturikova, 2015).

The method of getting gaming simulation becomes appropriate which not only helps students to adapt to new conditions, but also increases the level of competence in their future professional activities, "it should be noted that when using the method of gaming simulation for the teacher, it is important to be familiar with the features of future professional activity of trainees, because its contents should, in our view, determine the forms and methods of teaching in the classroom" (Sturikova, Albrekht, Kondyurina, Rozhneva, Sankova, Morozova, 2016), and to promote the effective adaptation of the first-year students to the study of linguistic disciplines, "that is explained by the characteristics of the subjects, whose main goal is to train languages as means of all participants' communication" (Kondyurina, 2009). From the discussion forms of work, we select the "debate" where it is assumed "exchange the views while discussing a topic or problem" (Sturikova, 2015). This form of training is not a template nonstandard character, which is also contributed to the maintenance of interest not only to the subject, but to the chosen profession. "On the one hand, such an approach combines the strict formal methods of teaching, like 
classroom work and the study of language materials, with informal ones" (Evtyugina, Simonova, Fedorenko, 2016).

The purpose of the experimental work: to verify the level of adaptation of the first-year students to the study of linguistic disciplines in the framework of FSES of $\mathrm{HE}$ of a new generation.

It is very common that graduates come from small towns to get higher education, so apart from the general difficulties common to all first-year students: increased academic workload, difficulties in the assimilation of new disciplines, the unusual level of the material, the complexity of relationships in the new team, to build a completely new system of relations with teachers, appeared the problems of private character: more fast paced life in the metropolis, the constant presence among many people, accommodation in student's hostel, etc.

Adaptation difficulties can be typical for all University students and is typical only for the first-year students. Such difficulties can be attributed to stress encountered in the transition of school graduates to another educational organization. The typical problems of the first-year students' adaptation include:

1) increase in the total volume of academic load, overload training sessions;

2) difficulty in the new linguistic disciplines assimilation, inability to organize themselves;

3) difficulty of defending their point of view;

4) difficulty in performing independent work, search new information;

5) complexity of relationships in the new team, getting used to new surroundings, to new people;

6) building system of relationships with new teachers;

7) difficulty in adapting to new living conditions.

We have interviewed 100 first-year students in the course of experimental work (61 of them came to study from other towns and cities of our country). Students answer the questions of a questionnaire on the difficulties they faced at the beginning of studies at the University, and the factors that helped students to adapt to new conditions. The analysis of the negative factors and the discussion of the results of the survey were held. Table 1 presents the negative factors of the first-year students' adaptation to the conditions of study at the University (indicators), levels of adaptation of students in each indicator and the final level of adaptation of the firstyear students to conduct experimental work, expressed in $\%$.

Table 1: The level of the first-year students' adaptation before the conduction of the experimental work

\begin{tabular}{|c|c|c|c|}
\hline $\begin{array}{c}\text { Negative factors } \\
\text { (indicators) / Levels }\end{array}$ & $\begin{array}{l}\text { Below } \\
\text { average } \\
(\%)\end{array}$ & Medium & $\begin{array}{l}\text { Above } \\
\text { average } \\
(\%)\end{array}$ \\
\hline $\begin{array}{c}\text { 1) Increase of total load, the } \\
\text { overload training sessions; }\end{array}$ & 33 & 45 & 22 \\
\hline $\begin{array}{c}\text { 2) Difficulty in the assimilation of } \\
\text { the new linguistic disciplines, inability } \\
\text { to organize themselves; }\end{array}$ & 23 & 37 & 40 \\
\hline $\begin{array}{c}\text { 3) Difficulty of defending their } \\
\text { point of view; }\end{array}$ & 34 & 32 & 34 \\
\hline $\begin{array}{c}\text { 4) Difficulty in performing } \\
\text { independent work, search information; }\end{array}$ & 27 & 31 & 42 \\
\hline $\begin{array}{c}\text { 5) Difficulty in relationships in the } \\
\text { team, getting used to new } \\
\text { surroundings, to new people; }\end{array}$ & 17 & 17 & 66 \\
\hline
\end{tabular}




\begin{tabular}{|c|c|c|c|}
\hline $\begin{array}{c}\text { 6) Building the system of } \\
\text { relationships with new teachers ; }\end{array}$ & 18 & 19 & 63 \\
\hline $\begin{array}{c}\text { 7) ) Difficulty in adapting to new } \\
\text { living conditions; }\end{array}$ & 29 & 59 & 12 \\
\hline The final level of adaptation & 25,9 & 34,3 & 39,8 \\
\hline
\end{tabular}

$78 \%$ of students (the level of adaptation is below average and medium) responded that they initially had great difficulty in all disciplines, including linguistic, due to the increase of workload, a large volume of information, more active supply of educational material, the lack of a daily survey of knowledge. Great difficulties were caused by the addiction to a time period lesson ( 90 minutes instead of 45 as in school).

$60 \%$ of students (the level of adaptation is below average and medium) spoke about the difficulties in the assimilation of new, not previously known, disciplines (for example, scientific style of speech, etc.).

$66 \%$ of students (the level of adaptation is below average and medium) spoke about the difficulties of public speaking, especially in the classroom, relevant to the humanitarian cycle, where it is necessary to express not only common in this particular science point of view, but also to discuss with the group their point of view on the issue and discuss it with the group. For many students it was almost impossible task.

$58 \%$ of students (the level of adaptation is below average and medium) noted difficulties in carrying out independent work, finding out sources of information; noted the inability to work with library catalog, to identify the important and necessary information in the articles, tutorials on a specific issue; learning the unfamiliar terms and difficult definitions for understanding.

$34 \%$ of students (the level of adaptation is below average and medium) spoke about the difficulty in building relationships with a new team, the fear to express themselves, to express their point of view.

$37 \%$ of students (the level of adaptation is below average and medium) spoke about the difficulty in building relationships with new teachers;

$88 \%$ of students (the level of adaptation is below average and medium), living in a hostel, have said that they felt the problem of adaptation in living conditions.

\subsection{Indicators of adaptation of students to the linguistic disciplines}

We took three levels of adaptation of students, which based on diagnostic tools: below average, medium, above average. The first- year students' adaptation to the study of linguistic disciplines in the framework of FSES of HE of a new generation was assessed by seven indicators: it was possible to get from 1 to 3 points for each indicator after conducting experimental work, which is expressed in $\%$.

Table 2. The level of the first-year students' adaptation after conducting experimental work

\begin{tabular}{|c|c|c|c|c|}
\hline $\begin{array}{c}\text { Negative factors (indicators) / } \\
\text { Levels }\end{array}$ & $\begin{array}{l}\text { Below } \\
\text { average }\end{array}$ & Medium & $\begin{array}{l}\text { Above } \\
\text { average } \\
\text { (\%) }\end{array}$ & \\
\hline $\begin{array}{c}\text { 1) Increase of total load, the } \\
\text { overload training sessions; }\end{array}$ & 21 & 53 & 26 \\
\hline $\begin{array}{c}\text { 2) Difficulty in learning the new } \\
\text { linguistic disciplines, inability to }\end{array}$ & 12 & 46 & 42 \\
\hline
\end{tabular}

XLinguae, Volume 10, Issue 4, October 2017, ISSN 1337-8384, eISSN 2453-711X 


\begin{tabular}{|c|c|c|c|}
\hline organize themselves ; & 19 & 43 & 38 \\
$\begin{array}{c}\text { 3) Difficulty of defending their } \\
\text { point of view; }\end{array}$ & 17 & 37 & 46 \\
\hline $\begin{array}{c}\text { 4) Difficulty in performing } \\
\text { independent work, information } \\
\text { retrieval; }\end{array}$ & 9 & 23 & 68 \\
$\begin{array}{c}\text { 5) Complexity of relationships in } \\
\text { new team, getting used to new } \\
\text { surroundings, new people; }\end{array}$ & 12 & 23 & 65 \\
\hline $\begin{array}{c}\text { 6) Building the system of } \\
\text { relationships with new teachers; }\end{array}$ & 21 & 64 & 15 \\
\hline $\begin{array}{l}\text { 7) Difficulty in adapting to new } \\
\text { living conditions }\end{array}$ & 14,4 & 41,6 & 44 \\
\hline
\end{tabular}

Table 2 shows that for all indicators the number of students with a level of adaptation below average has decreased and the number of students with a medium level of adaptation and above average has increased.

For the purpose of effective adaptation of the first-year students to the study of linguistic disciplines at the University we tried to identify not only negative, but also positive adaptation factors. About $50 \%$ of the students identified the following favorable factors: organization of the work of tutors, the creation of tutors advice for the first-year students, positive teachers' attitude to the first-year students, various activities outside the classroom where freshmen can express themselves, discover their abilities, the result can be new, informal relationships with fellow students; students distinguish, for example, competitions "Best speaker", "Golden pen", "Inspiration", "Round table on linguistics", debates, Olympiad etc. and Extracurricular activities is considered as a "continuation of the educational process in general" (Degtyarenko, 2015).

All events and competitions are of informative and educational interest, as well as contribute to the effective adaptation of students. The system of educational work, professional and corporate communication, mentoring, student governments have helped to the first-year students quickly adapt to the educational process at the University ((Dorozhkin, Zaitseva \& Tatarskikh, 2016).

Thus, the developed and introduced in educational process the complex of actions allows the first-year students quickly adapt to the new conditions of University studies in general and to the study of linguistic disciplines in particular.

\section{Conclusion}

In the result of experimental work it was found that

1. The lack of adaptation of the first-year students' adaptation to educational process at the University negative affects the formation of the future specialist.

2. The adaptation stage at the University cannot be considered as spontaneously formed interaction of a student with the classmates, tutors, teachers, it represents a guided process, which based on the relevant performance indicators.

3. The specially developed complex of actions is necessary and sufficient for the efficient adaptation of the first-year students.

4. The obtained results are summarized, the effectiveness of theoretical and practical propositions of study are experimentally proved, which contained the positive dynamics of students' adaptation to the study of linguistic disciplines.

The promising direction of research is the establishment of a program of the first-year students' adaptation to the study of linguistic disciplines in the framework 
of realization of Federal state educational standards in higher education (FSES in HE) of a new generation.

\section{Acknowledgement}

The significance of this research lies in the fact that the obtained results allow to clarify the essence of the concepts "student's adaptation", "the effectiveness of student's adaptation"; scientifically substantiate and develop a complex of measures for effective adaptation of students (the first-year students' adaptation) to the study of linguistic disciplines;

The materials of this article may be useful in practical work for teachers of the linguistic disciplines not only at the universities, but also at schools, colleges, and may be interested for psychologists in the system of education and everybody who are connected with the professional pedagogical activity.

During the research there were some problems that need consideration. It is necessary to continue research of the first-year students' adaptation to study at vocational higher educational institution in the context of realization of Federal state educational standards of higher education (FSES in HE) of a new generation.

\section{Bibliograpic references}

AFONINA, T.N. - UVAROVA, V. I. 2001. Socio - psychological and professional adaptation of students of universities in Central region of Russia. Orel: GAU, 197 p.

ALYOKHIN, A.N. - ANDRUSHEVICH, O.V. 2009. Medico - psychological aspects of adaptation of students to training in higher school. In: Universum: Bulletin of Herzen University, vol. 12, pp. 22-25. ISSN 1997-8588.

ASTRAHANCEVA, T.S. - SHINKARUK, M.V. 2015. Indicators of adaptation of students - freshmen to study at the University. Scientific and technical creativity of students and postgraduates: proceedings of the 45 th scientific-technical conference of students and postgraduates, 36 - 38 . Available online: https://altstu.ru/structure/chair/aiah/sciencework/

CAI, J., - YOUNGBLOOD, V.T. - KHODYREVA, E.A. KHUZIAKHMETOV, A.N. 2017. Higher Education Curricula Designing on the Basis of the Regional Labour Market Demands. In: EURASIA Journal of Mathematics, Science and Technology Education, vol. 13, n. 7, pp. 2805-2819. ISSN: $13058215,13058223$.

CAO, Y. - KIRILOVA, G.I. - GRUNIS, M.L. 2017. Cooperative Research Projects of Master's Students (Education Programs) in the Open Informational Educational Environment. In: EURASIA Journal of Mathematics, Science and Technology Education, vol. 13, n. 7, pp. 2859-2868. ISSN: 13058215, 13058223.

DEGTYARENKO, V. V. 2015. Extracurricular work with foreign students as a way of social adaptation to learning in medical higher school. Available online: http://weblocal.rudn.ru/web-local/uem/iop_pdf/253-Gladush.pdf

DEMANOVA, I. B. - SIDORENKO, E. V. 2003. Interpersonal relationships. The psychological workshop. Saint Petersburg: Speech. 23 p.

DOROZHKIN, E.M. - ZAITSEVA, E.V. - TARASKIKH, B.Y. 2016. Impact of Student Government Bodies on Students' Professional Development. In: IEJMEMathematics Education, vol. 11, n. 7, pp. 2666-2677. ISSN : 2468-4945.

EVTYUGINA, A.A. - SIMONOVA, M.V. - FEDORENKO, R.V. 2016. Teaching Conversational Language Skills to Foreign Students: Blended Learning and Interactive Approaches. In: IEJME-Mathematics Education, vol.11, n. 8, pp. 29252936. ISSN : 2468-4945. 
EZROKH J.S. 2014. The game technique ntchnique stimulating learning activity of junior students specializing in economics. In: The Education and science journal, vol. 7, pp. 87-102. ISSN 2227-7102.

FEDOROV, V.A. 2000. Extra-curricular work with foreign students as a way of social adaptation to training in medical higher education. In: The Education and science journal, vol. 2, n. 4, p. 60-68. ISSN 2227-7102.

GAPONOVA, S. A. 1994. Features of adaptation of students in the learning process. In: Psychological journal, vol. 15, n. 3, 131-135.

GOLUBKOVA, O.N. - MASALIMOVA, A.R. - BIROVA, J. (2017). The Development of Sociocultural Competence in Future Translators Via the Methodology of Culture-Oriented Interpretation of English Language Fictional Texts. In: Man In India, vol. 97, n. 14, pp. 73-83. ISSN: 00251569.

GORBUNOVA, N.V. - MOKEYEVA, E.V. 2017. Innovative Educational Environment of Higher Educational Institution. In: Man In India, vol. 97, n. 15, pp. 21-40. ISSN: 00251569.

HOARE, S. 2006. Universities adapt to a shrinking world. Available online: www.guardian.co.uk/education/2006/mar/07/elearning.technology

HOARE, S. 2006. Universities adapt to a shrinking world. Available online: www.guardian.co.uk/education/2006/mar/07/elearning.technology14

KAZAKOV, A.V. - ZAKIROVA, V.G. - BIROVA, J. 2017. Modeling the Process of Forming Social and Cultural Competence among Students of Linguistics Faculty. In: Man In India, vol. 97, n. 14, pp. 291-305. ISSN: 00251569.

KODZHASPIROVA, G.M. - KODZHASPIROV, A.U. (2001). Pedagogical dictionary. Moscow: Publishing center "Academy". 176 p.

KONDYURINA, I.M. 2012. Technology of preparation of the mobile specialist in the process of learning foreign language communication in modern times. Replication of the culture of the society in the context of vocational education. Stavropol: publishing house of the St. George Institute of technology (branch) of FGBOU VPO "the North Caucasus fed. Univ", pp. 128-137.

KRUCHININA, G.A. - DARYENKOV, N.N. 2016. The first-year students' adaptation to study at a technical University in the condition of informatization of education. Nizhny Novgorod: publishing house of NNSASU. 178 p.

KUSAKINA, S.N. 2011. Psychological readiness to study at the University. In: Pre school educational institution's management, vol. 8, pp. 24-37. ISSN: 2220-1483.

KUZMISHKIN, A.A. 2014. The first-year students' adaptation at the University. In: A young scientist, vol. 3, pp. 933-935. 2409-2525

LAVRINENKO, S.V. 2014. Prospects of tutorial activities in modern conditions of technical universities development. In: the world of scientific discoveries, vol. $3, \mathrm{n}$. 51, pp. 278-282. ISSN 2072-0831.

LESNIKOVA, S.L. - BELYANINA, I.N. 2011. Overcoming students ' cognitive barriers as a condition of their successful adaptation to learning at the university. In: Bulletin of the Kemerovo state University of culture and arts, vol. 4, n. 17, 159-163. ISSN 2078-8975.

LI, N. - PYRKOVA, K.V. -- RYABOVA, T.V. 2017. Teaching Communication Skills and Decision-Making to University Students. In: EURASIA Journal of Mathematics, Science and Technology Education, vol. 13, n. 8, pp. 4715-4723. ISSN: $13058215,13058223$.

MOLOKOVA O.A. 2015 Psychological diagnostics of students adaptation to university studies. In: The Education and science journal, vol. 10, pp.146-156. ISSN 1994-5639. DOI:10.17853/1994-5639-2015-10-146-156

MORALES, A. 2009. Why universities should adapt to students. Available online: www.blog.orgsync.com/2009/

NALIVAIKO, T.E. - SHINKORUK, M.V. 2014. Monitoring of students ' adaptation to educational process at the University as a tool for their academic success. In: 
Scientific notes of Komsomolsk-on-Amur state technical University, vol. 1, n. 17, pp. 28-33. ISSN 2303-9868.

NOVIKOVA, Z. N. 2016. Psychological characteristics of the first-year students' adaptation to training in higher educational institution in VGLTU. In: Modern technologies ensure of civil defense and elimination of emergency situations' consequences, vol. 2, n. 7, pp. 290-294. ISSN: 2224-8617.

RADNAEVA, M.V. - SHIBANOVA, U.V. 2016. To the question of students' adaptation at the initial stage of training in higher school. In: Bulletin of the Buryat state University, vol. 1, pp. 44-49. ISSN 1994-0866.

SEDIN, V.I. - LEONOVA, E.V. 2009. Students' adaptation to training in higher school: psychological aspects. In: Higher education in Russia, vol. 7, pp. 83-89. ISSN 0869-3617.

SHEN, P. - GROMOVA, C.R. - ZAKIROVA, V.G. - YALALOV, F.G. 2017. Educational Technology as a Video Cases in Teaching Psychology for Future Teachers. In: EURASIA Journal of Mathematics, Science and Technology Education, vol. 13, n. 7, pp. 3417-3429. ISSN: 13058215, 13058223.

SHEVELEVA, A.M. 2014. To the question of the first-year students' adaptation to study at the University. In: The Council of rectors, vol. 4, pp. 55-69. ISSN 0024-2667. SIPPEL, S. 2007 Entwicklung, psychometrische Überprüfung und Validierung einer deutschen Fassung des "Student Adaptation to College Questionnaire SACQ" von R.W. Baker und B. Syrik. Verlag: GRIN Verlag. 120 p.

SMIRNOV, A.G. 1998. The problems of occurrence of socio-psychological dynamics of students' adaptation to the University. In: Psychological conditions of personality's professional formation in the light of the reform of general and vocational education, vol. 1, pp. 48-55. ISSN: 2224-0772.

STURIKOVA, M.V. 2015. The use of the interactive teaching methods in the development of learners' communicative competence. In: Municipal education: innovation and experiment, vol. 2, pp. 38-41. ISSN 2306-8310.

STURIKOVA, M.V. - ALBREKHT, N.V. - KONDYURINA, I.M. - ROZHNEVA, S.S. - SANKOVA, L.V. - Morozova, E.S. 2016. Formation of Future Specialists' Communicative Competence in Language Disciplines Through Modeling in Game of Professional Situations. In: International Journal of Environmental and Science Education, vol. 11, n. 15, pp. 7826-7835. ISSN: 1306-3065.

VOLKOVA N.V. 2017. Technology of educational events designing. In: The Education and science journal, vol. 4, pp.184-200. DOI:10.17853/1994-5639-2017-4184-200 ISSN 2227-7102.

ZINCHENKO, V.P. 2007. Psychological dictionary. Saint Petersburg: Price, Evroznak, 672 p.

Words: 7603

Characters: 51635 (28,68 standard pages)

Prof. Marina V. Sturikova, PhD,

Prof. Nina V. Albrekht, PhD,

Prof. Irina M. Kondyurina, $\mathrm{PhD}$,

Prof. Alena A. Evtugina, PhD,

Professor of the Department of Russian and Foreign Languages

of the Institute of Psychology and Education in

Russian State Vocational Pedagogical University

11 Mashinostroiteley street

620012 Ekaterinburg

XLinguae, Volume 10, Issue 4, October 2017, ISSN 1337-8384, eISSN 2453-711X 
Russia

sturikova_marina@mail.ru

n_albrekht@mail.ru

im.kon@mail.ru

alena.seven@mail.ru

Svetlana V. Smirnova

Department of Russian and Foreign Languages

of the Institute of Psychology and Education in

Russian State Vocational Pedagogical University

11 Mashinostroiteley street

620012 Ekaterinburg

Russia

kaf_rus_yaz@mail.ru 